\title{
Multi-material Preforming of Structural Composites
}

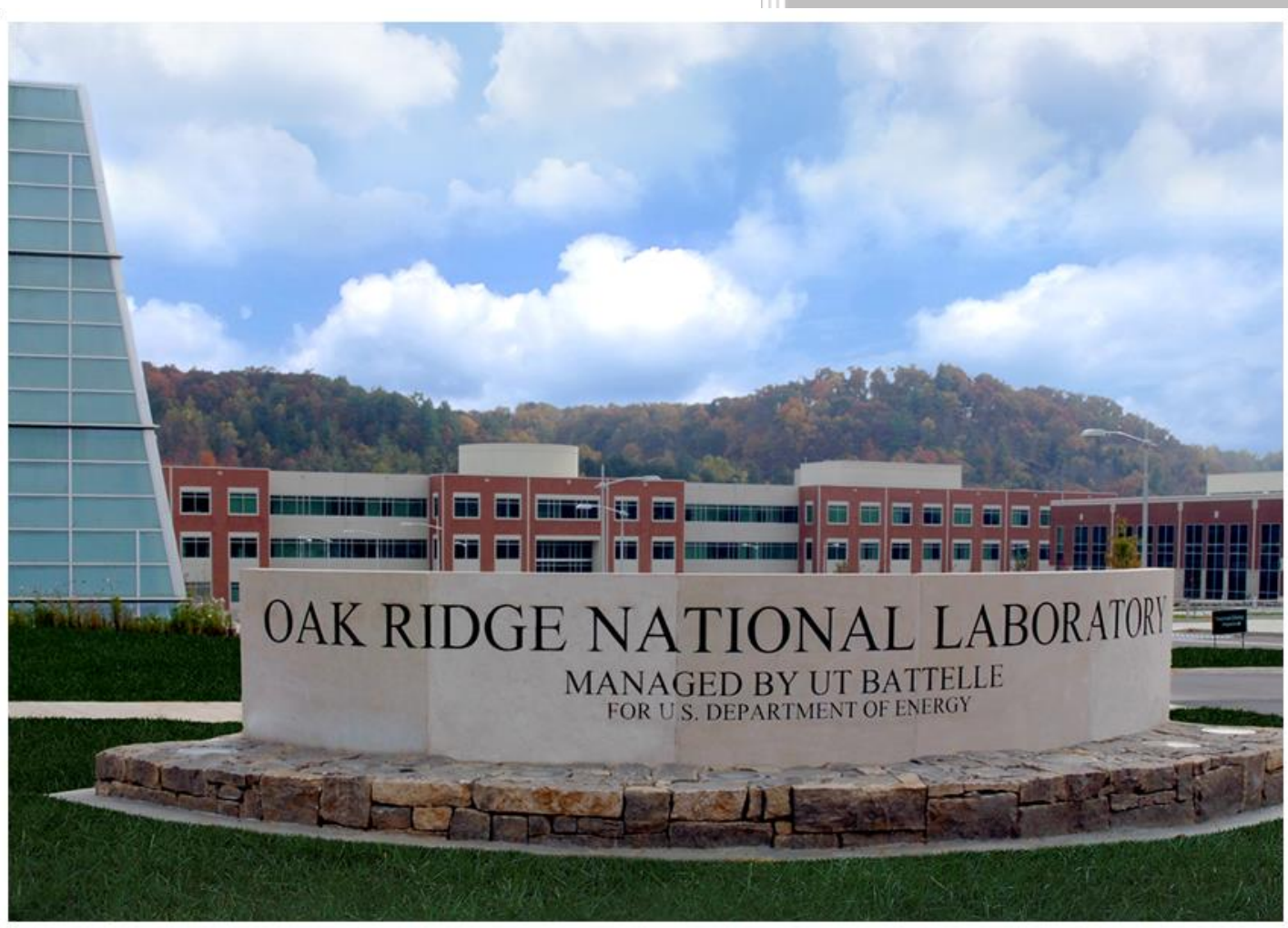

\section{CRADA FINAL REPORT NFE-14-04920}

Approved for Public Release. Distribution is Unlimited.
R. E. Norris

April 13, 2015 


\title{
DOCUMENT AVAILABILITY
}

Reports produced after January 1, 1996, are generally available free via US Department of Energy (DOE) SciTech Connect.

Website http://www.osti.gov/scitech/

Reports produced before January 1, 1996, may be purchased by members of the public from the following source:

\author{
National Technical Information Service \\ 5285 Port Royal Road \\ Springfield, VA 22161 \\ Telephone 703-605-6000 (1-800-553-6847) \\ TDD 703-487-4639 \\ Fax 703-605-6900 \\ E-mail info@ntis.gov \\ Website http://www.ntis.gov/help/ordermethods.aspx
}

Reports are available to DOE employees, DOE contractors, Energy Technology Data Exchange representatives, and International Nuclear Information System representatives from the following source:

Office of Scientific and Technical Information

PO Box 62

Oak Ridge, TN 37831

Telephone 865-576-8401

Fax 865-576-5728

E-mail reports@osti.gov

Website http://www.osti.gov/contact.html

This report was prepared as an account of work sponsored by an agency of the United States Government. Neither the United States Government nor any agency thereof, nor any of their employees, makes any warranty, express or implied, or assumes any legal liability or responsibility for the accuracy, completeness, or usefulness of any information, apparatus, product, or process disclosed, or represents that its use would not infringe privately owned rights. Reference herein to any specific commercial product, process, or service by trade name, trademark, manufacturer, or otherwise, does not necessarily constitute or imply its endorsement, recommendation, or favoring by the United States Government or any agency thereof. The views and opinions of authors expressed herein do not necessarily state or reflect those of the United States Government or any agency thereof. 
ORNL/TM-2015/174

CRADA/NFE- 14-04920

Materials Science and Technology Division Advanced Manufacturing Office

\title{
Multi-material Preforming of Structural Composites
}

\author{
Authors \\ R. E. Norris \\ C. C. Eberle \\ C. Pastore \\ Thomas Z. Sudbury \\ F. Xiong \\ D. Hartman
}

Date Published:

April 2015

Prepared by

OAK RIDGE NATIONAL LABORATORY

Oak Ridge, Tennessee 37831-6283

managed by

UT-BATTELLE, LLC

for the

US DEPARTMENT OF ENERGY

under contract DE-AC05-00OR22725

Approved For Public Release 


\section{CONTENTS}

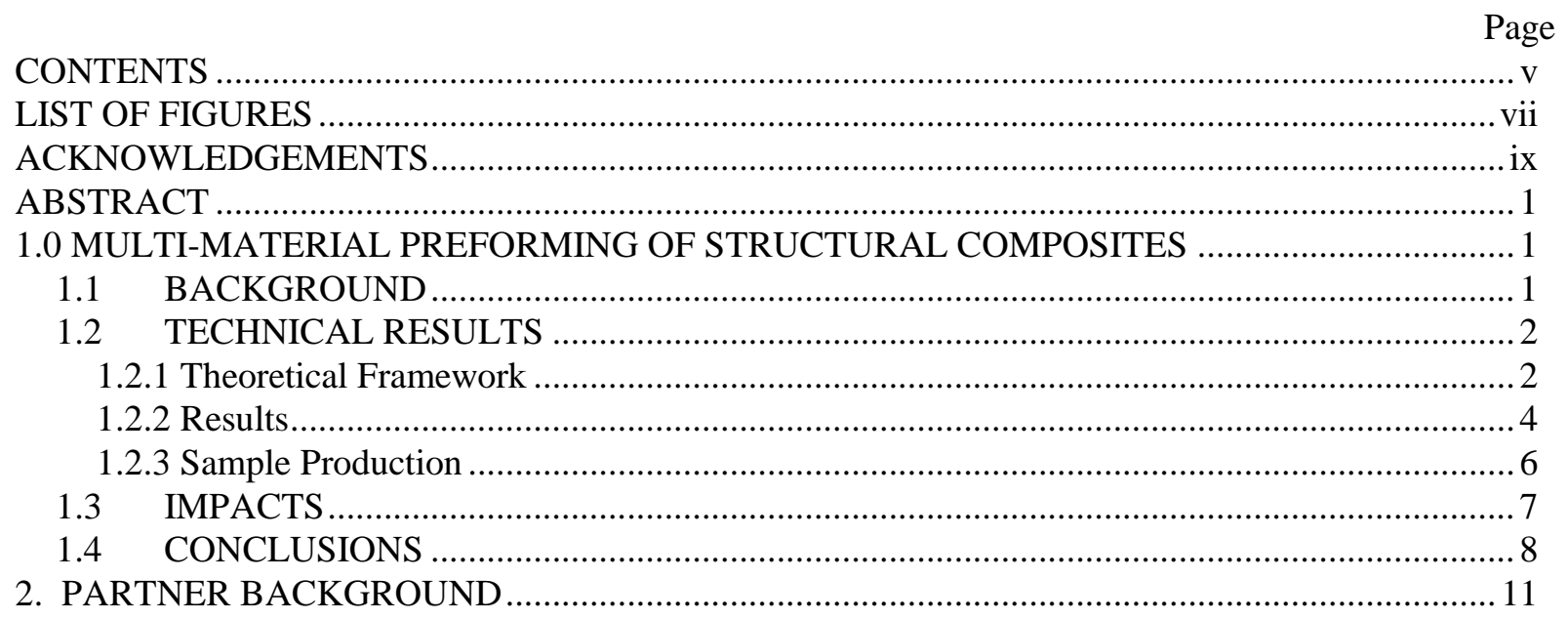




\section{LIST OF FIGURES}

Figure 1. Tensile strength of hybrid materials comparing theory and experiment. At least 20 samples were tested for each degree of hybridization. 3

Figure 2. Tensile modulus of hybrid materials comparing theory and experiment. Each data point

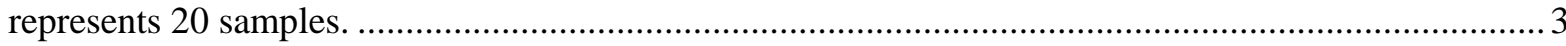

Figure 3. Required thickness for hybrid composites to have same bending stiffness as carbon

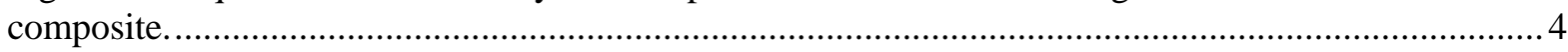

Figure 4. Cost vs. Weight of stiffness equivalent hat-section beams subject to central loading. ...........5

Figure 5. Effective cost of stiffness equivalent parts as a function of weight penalty........................... 6

Figure 6. Male section on left and female on right from 3D printed mold........................................ 6

Figure 7. Quadratic hybrid, linear hybrid, and all carbon reinforced hat sections................................ 7

Figure 8. Results of hat section testing at Owens Corning........................................................... 8 


\section{ACKNOWLEDGEMENTS}

This CRADA NFE-14-04920 was conducted as a Technical Collaboration project within the Oak Ridge National Laboratory (ORNL) Manufacturing Demonstration Facility (MDF) sponsored by the US Department of Energy Advanced Manufacturing Office (CPS Agreement Number 24761).

Opportunities for MDF technical collaborations are listed in the announcement "Manufacturing Demonstration Facility Technology Collaborations for US Manufacturers in Advanced Manufacturing and Materials Technologies" posted at http://web.ornl.gov/sci/manufacturing/docs/FBO-ORNL-MDF2013-2.pdf. The goal of technical collaborations is to engage industry partners to participate in shortterm, collaborative projects within the Manufacturing Demonstration Facility (MDF) to assess applicability and of new energy efficient manufacturing technologies. Research sponsored by the U.S. Department of Energy, Office of Energy Efficiency and Renewable Energy, Advanced Manufacturing Office, under contract DE-AC05-00OR22725 with UT-Battelle, LLC.

The authors would like to recognize the rapid, innovative, and inexpensive mold production at the ORNL MDF by Vlastimil Kunc and Lonnie Love and the testing conducted at Owens Corning by Tom Offenbaker supported by Mala Nagarajan. 



\begin{abstract}
Fiber-reinforced composites offer significant weight reduction potential, with glass fiber composites already widely adopted. Carbon fiber composites deliver the greatest performance benefits, but their high cost has inhibited widespread adoption. This project demonstrates that hybrid carbon-glass solutions can realize most of the benefits of carbon fiber composites at much lower cost. ORNL and Owens Corning Reinforcements along with program participants at the ORISE collaborated to demonstrate methods to produce hybrid composites along with techniques to predict performance and economic tradeoffs. These predictions were then verified in testing coupons and more complex demonstration articles.
\end{abstract}

\title{
1.0 MULTI-MATERIAL PREFORMING OF STRUCTURAL COMPOSITES
}

This Phase 1 technical collaboration project (MDF-TC-2013-030) was approved by AMO on September 24, 2013 and was completed on March 4, 2015. The collaboration partner, Owens Corning Science and Technology, LLC is a large business. This project demonstrates that hybrid carbon-glass solutions can realize most of the benefits of carbon fiber composites at much lower cost.

\subsection{BACKGROUND}

Weight has a cost penalty (or conversely, weight reduction has a value or premium), depending on the application. The relatively high cost of composites is a barrier to their adoption in cost-sensitive (low weight penalty) energy applications. Multi-material preforming enables the production of composite components with increased structural efficiency and reduced cost. This will accelerate the deployment of high performance composites in energy applications.

Lightweight design and construction is essential for maximizing performance in many energy applications. For example, a 10\% mass reduction in passenger automobiles reduces fuel demand by about $6-8 \%^{1}$, hence routes to compliance with 2025 U.S. CAFÉ regulations $(54.5 \mathrm{mpg}$ ) typically include demanding vehicle weight reduction targets. Similarly, utility scale wind turbines are growing larger with prototype blades approaching $100 \mathrm{~m}$ long, requiring a combination of low mass and stiffness that can only be delivered by fiber-reinforced composites, with carbon fibers being very desirable for high stiffness.

Carbon fiber composites maximize weight reduction in these applications, but at a very high cost premium. Most structural parts are over-designed with the entire material volume able to withstand the highest stress levels in the part. However, the parts rarely experience uniform stress - some areas are much more stressed than others. An optimized part can be designed such that all of the material approaches the design limit condition in at least one load case while never exceeding that limit in any load case. The use of a high precision, selective fiber placement technique can result in appropriately designed, minimal weight components. In an optimal configuration, lower cost materials can be incorporated in areas where benefits of the carbon fiber do not justify the cost premium, resulting in a reduced overall cost of production while fully satisfying all performance requirements.

This method has been realized in continuous fiber applications. Laminated composites often include glass at the core and carbon on the surface for bending resistance, and woven fabrics with glass in one

\footnotetext{
${ }^{1}$ Lynette W. Cheah, "Cars on a Diet: The Material and Energy Impacts of Passenger Vehicle Weight Reduction in the U.S.", Massachusetts Institute of Technology Ph.D. Thesis, Sept 2010
} 
direction and carbon in the other have been developed for applications with directional loading. However with continuous fiber composites there are limitations to the ability to vary the carbon and glass content. The use of short fiber deposition allows variation in carbon content in all dimensions of the part in an arbitrary pattern. Further short fiber deposition offers a significantly lower cost final product.

The optimized multi-materials solution approaches the all-carbon weight at lower cost for all carbon fiber price-property combinations considered. The obvious conclusion is that multi-materials solutions offer higher value than all-carbon solutions unless there is extreme value awarded for weight reduction.

\subsection{TECHNICAL RESULTS}

This project explored the optimization of cost and weight for composite materials subject to specific load conditions. In particular, this project focused on using the more expensive carbon fiber only where needed in a gradient hybrid material form. The goal is a process that allows automation while optimizing weight and cost for a given structural element.

Through a combination of theoretical and experimental evaluations, a methodology for evaluating the weight-cost efficiency of chopped fiber composites was developed and confirmed experimentally. Owens Corning was the industrial partner on this project, providing component design guidance, materials, and testing.

\subsubsection{Theoretical Framework}

The model required mechanical property predictions on a local level and the structural analysis for the component. Material property predictions were performed using a modified Mori-Tanaka model ${ }^{2}$ to generate stiffness properties. Strength predictions of the local material were performed using a strain to failure criteria combined with a blended material model.

To simulate the performance of a robotic fiber placement system such as could be implemented with ORNL's Programmable Powder Preform Process, or P4, robot system (manufactured by Aplicator System AB in Sweden), samples of fiber deposited by the robot were evaluated with image analysis software to determine the fiber orientation distribution. It was discovered that the robot has a slight bias towards one direction, and this orientation distribution function was used in the micromechanics model.

The modeled material properties were confirmed through experimentation. Tensile plates were produced at different uniform hybridization levels, combining chopped glass and chopped carbon fiber in an epoxy matrix. The glass fiber was Advantex ${ }^{\circledR}$ from Owens Corning, and the carbon was Panex ${ }^{\circledR}$ 35 from Zoltek. The composites plates produced were machined into tensile specimens and the local fiber volume fraction of each component was estimated by thickness measurements. For comparison purposes, all experimental data shown here has been normalized to 35\% fiber volume fraction.

Figure 1 shows the tensile strength of the hybrid composites as a function of the carbon fiber proportion of the composite section. Figure 2 shows the tensile modulus of the hybrid composites compared with the theoretical predictions. Agreement was good with both models. The standard deviation was relatively high in these specimens because of the fiber hybridization that was performed manually.

\footnotetext{
${ }^{2}$ Mori, T. and Tanaka, K. (1973). "Average Stress in the Matrix and Average Elastic Energy of Materials with Misfitting Inclusions". Acta metallurgica 21: 571-574.
} 


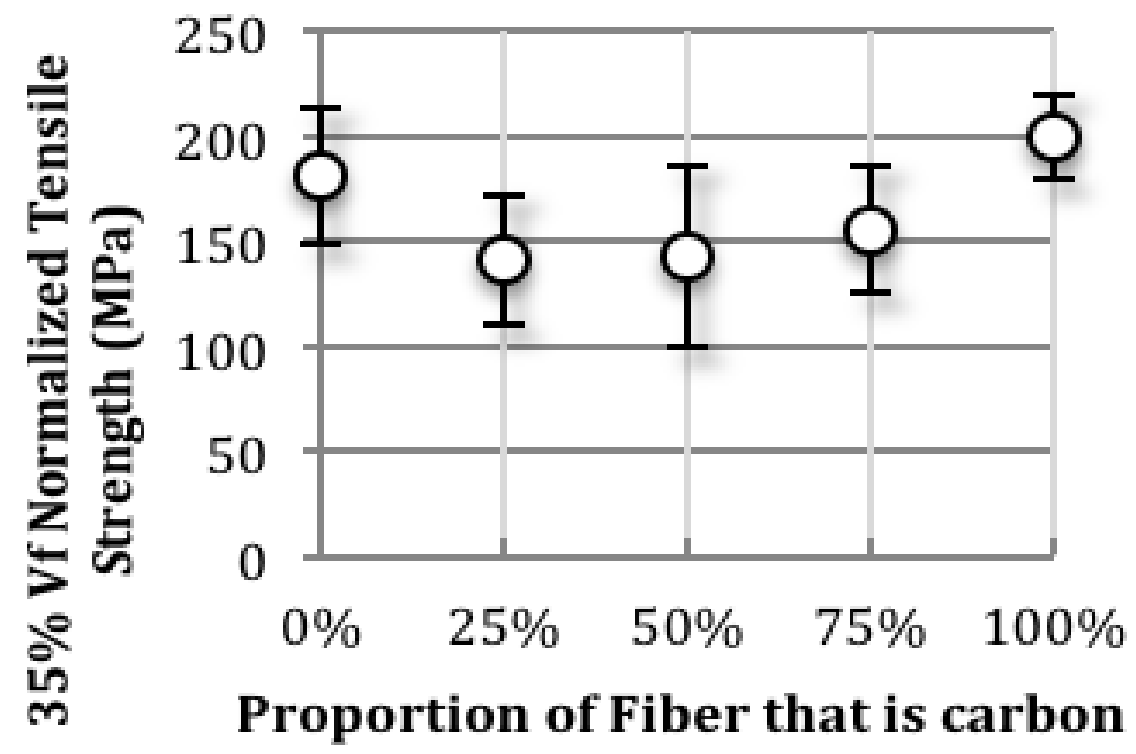

Figure 1. Tensile strength of hybrid materials comparing theory and experiment. At least 20 samples were tested for each degree of hybridization.

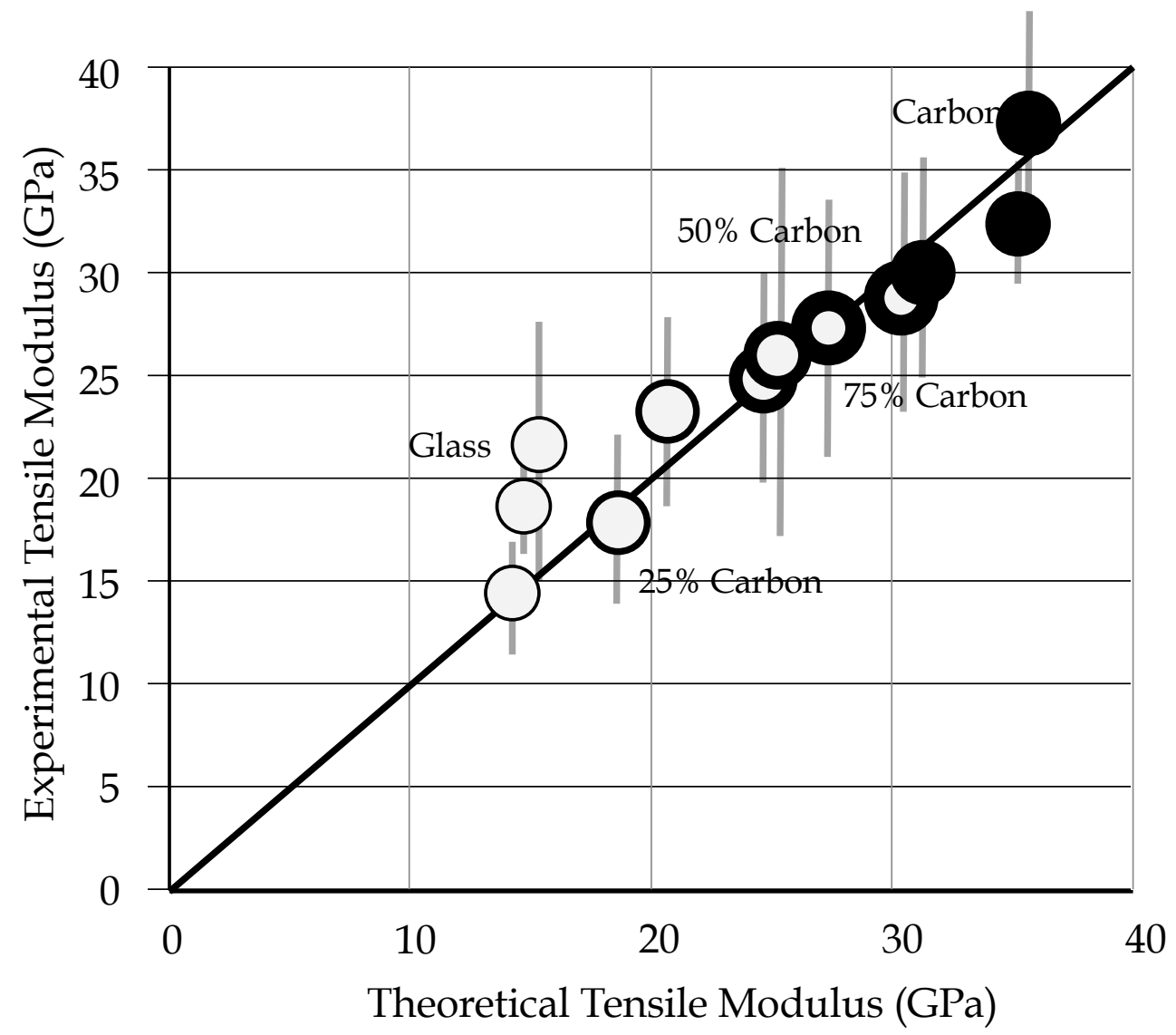

Figure 2. Tensile modulus of hybrid materials comparing theory and experiment. Each data point represents 20 samples. 
Structural analysis was performed for a simply supported hat section beam subject to a central point load. For the uniform materials this was performed analytically. For the structures with varying material properties down the length of the composite this was performed using a numerical method.

Optimized hybrids were considered that had a smooth gradient of material ranging from glass at the supports to carbon in the center. Two different variations were modeled - one varies carbon fiber content linearly to match the moment (hereafter referred to as Linear Hybrid) and the other varying the carbon fiber content quadratically (hereafter referred to as Quad or Quadratic Hybrid) to maximize the amount of glass fiber.

\subsubsection{Results}

For each configuration, the required thickness of the hat section to meet the same bending stiffness as an all carbon composite beam was calculated, and are presented in Figure 3. Also on this figure is the required thickness for a uniformly blended hybrid composite. It can be seen that the selective placement of fiber around the highest moments results in a weight savings of around 14\% compared to a uniformly blended hybrid with the same total material configuration.

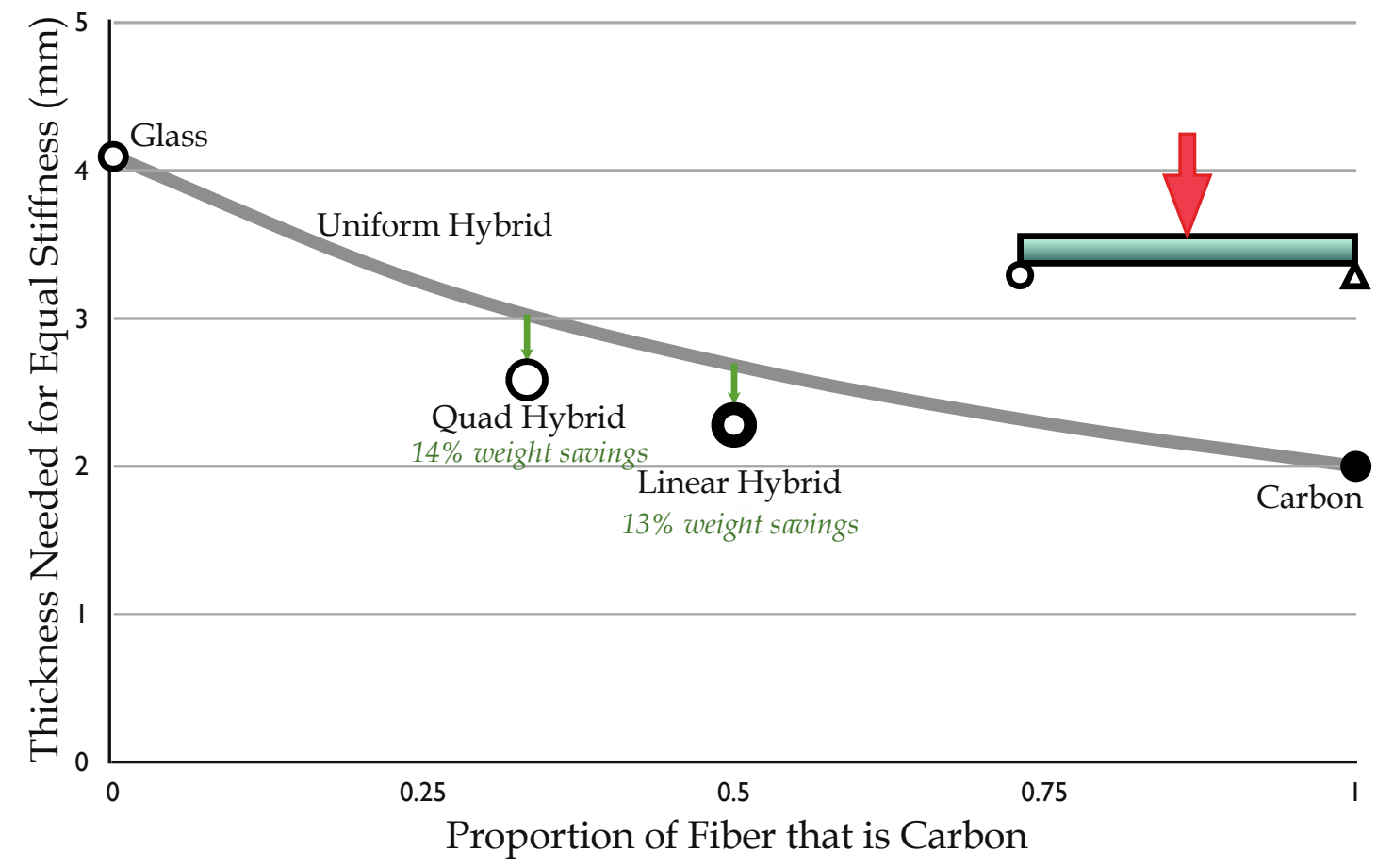

Figure 3. Required thickness for hybrid composites to have same bending stiffness as carbon composite.

From these calculations it is possible to estimate the materials cost of the different configurations as well as the weight of the component. A map of cost vs. weight shows the solution space of materials (Figure 4). The choice of optimal configuration is not readily available from this illustration. Each solution has an advantage - it may be lighter than another, but not less expensive. At the extremes, the carbon fiber solution reduces the mass by about $60 \%$ while increasing the cost by about a factor of 2.25 when compared to all glass. The linear and quadratic hybrids, however, reduce the mass by about $45-55 \%$ while increasing the cost by about $25-50 \%$. To determine which is best it is necessary to find an exchange constant that converts weight into cost - the penalty of carrying the extra weight. The 
value of this exchange constant will depend on the particular application.

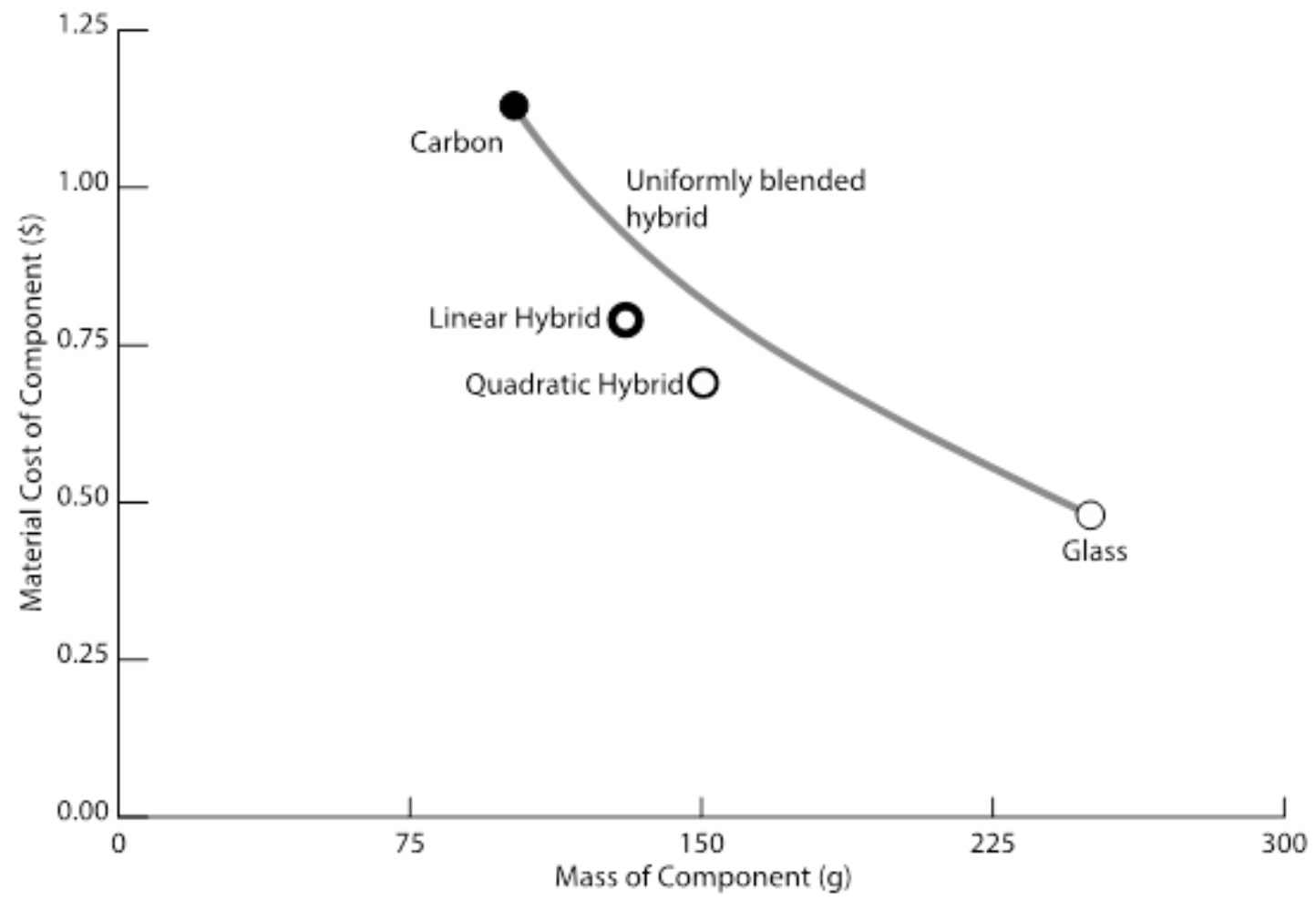

Figure 4. Cost vs. Weight of stiffness equivalent hat-section beams subject to central loading.

Figure 5 shows the effective cost of different hat section configurations as a function of the weight penalty. Depending on the value of weight, different materials appear optimal. When weight is valued between $\$ 1.00$ and $\$ 5.30$ per pound, the optimized hybrids offer the best solution to the problem.

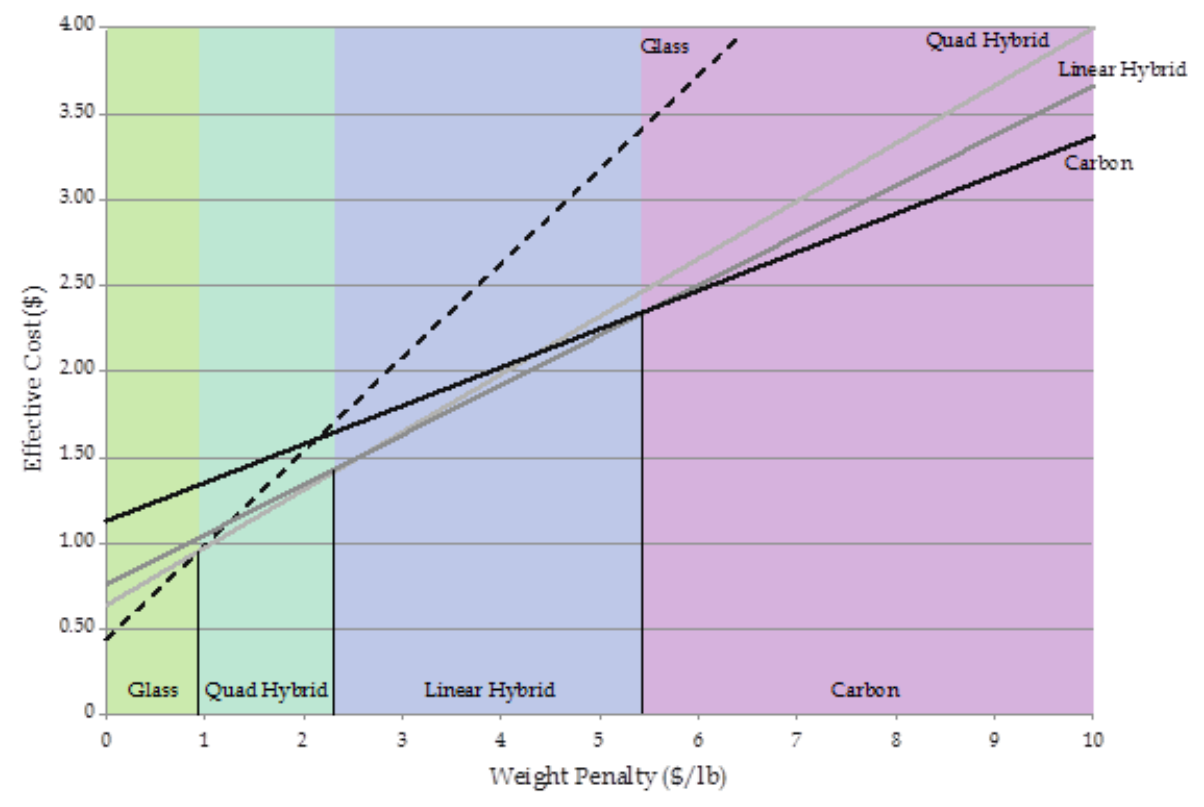


Figure 5. Effective cost of stiffness equivalent parts as a function of weight penalty.

\subsubsection{Sample Production}

A simple tool form mold was produced using 3D printing at the ORNL Manufacturing Demonstration Facility by Kunc and Love as shown in Figure 6. This 3D printing approach utilizing fused deposition modeling (FDM) had allowed the team to experiment with different tooling construction materials and geometric variations very rapidly before settling on the final configuration. The chosen configuration utilized Ultem 9085 and was printed within a 24-hour time period. This mold was utilized to produce hat-section samples as shown in Figure 7 representing the previously described approaches to hybridization along with all-carbon and all fiberglass (not shown) reinforced sections for comparative purposes. Fibers were manually mixed according to the desired fiber gradients and placed in the molds for consolidation. Zoltek standard modulus carbon fiber, Owens Corning E-Glass, and a general purpose epoxy structural resin were supplied by Owens Corning for this demonstration.

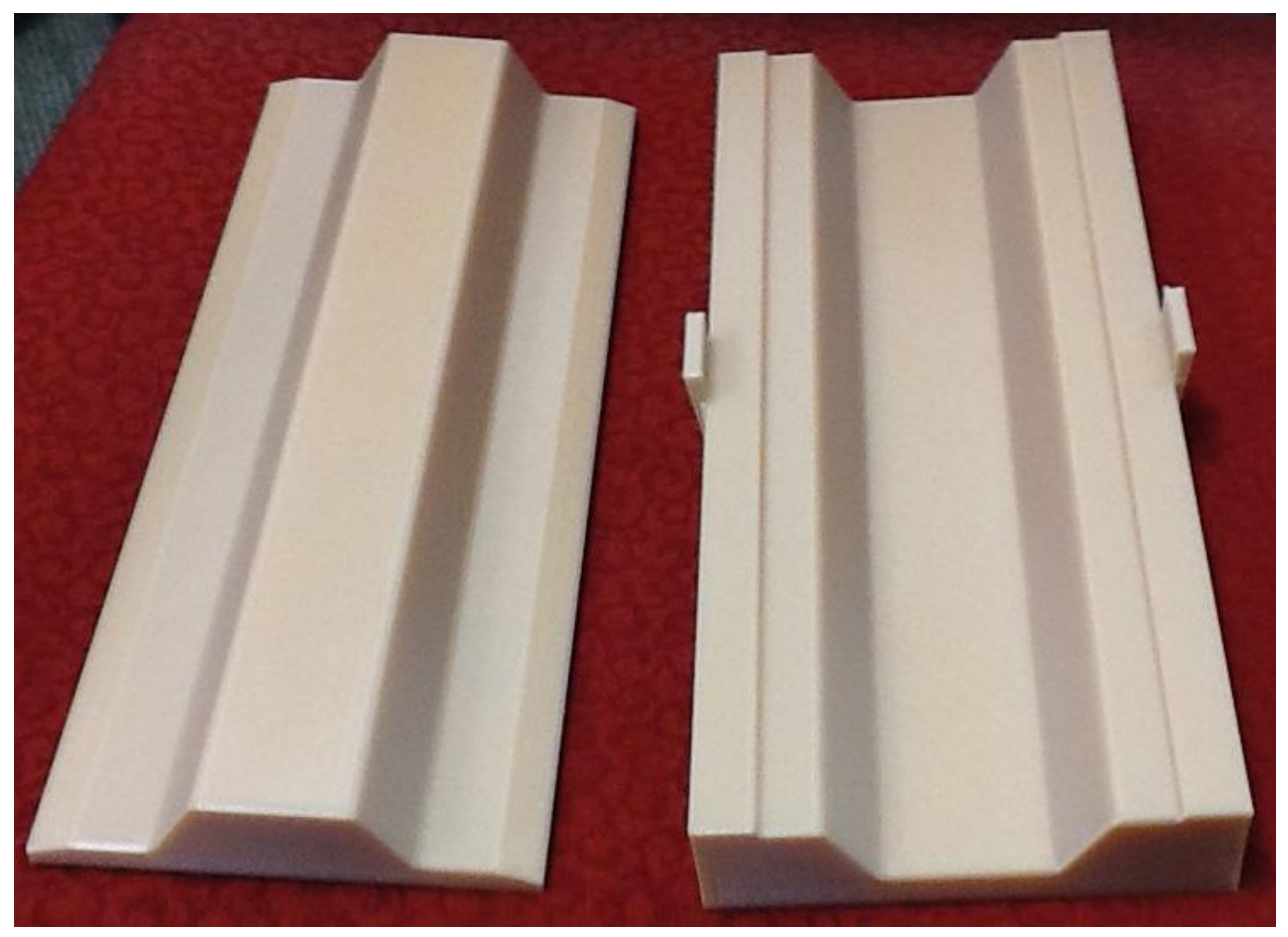

Figure 6. Male section on left and female on right from 3D printed mold.

The hat section samples were tested for flexural stiffness at Owens Corning along with some flat strip sections fabricated using the same hybridization approaches previously described. The samples were tested in 3-point bending with test conditions and methods customized based on and adapted from ASTM D 790-10. Because the fiber distribution in the samples was accomplished by hand deposition methods and the molds did not possess capability to precisely meter resin injection and control sample thickness, the samples had large variability in composition and geometry. When normalized to adjust for the thickness variability, the results as shown graphically in Figure 8 do support the trends as described earlier. 


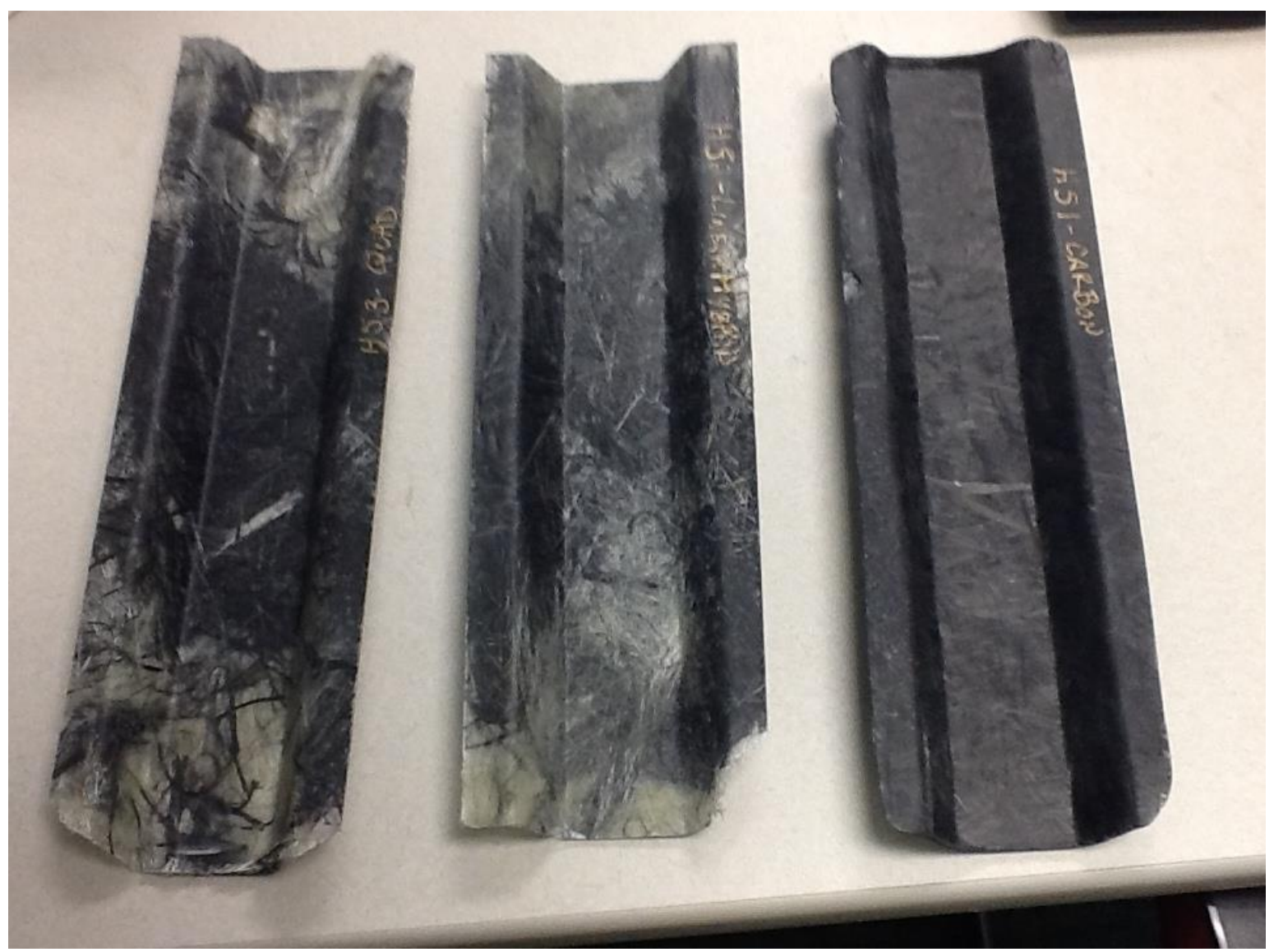

Figure 7. Quadratic hybrid, linear hybrid, and all carbon reinforced hat sections.

\subsection{IMPACTS}

Vehicle lightweighting is identified as a key pathway to energy savings where numbers frequently cited point to $10 \%$ mass reduction in passenger automobiles reducing fuel demand by about $6-8 \%$. Carbon fiber composites have potential to maximize weight reduction in these applications, but at a very high cost premium. Immediate wide-spread application of carbon fiber in automotive applications would quickly outstrip current carbon fiber production capacity even if the cost premium could be absorbed. Fiberglass composites have already gained significant inroads in automotive applications where the much larger existing capacity of fiberglass producers can easily meet demands. Producers such as Owens Corning (world's largest fiberglass producer) recognize that synergistic utilization of carbon and fiberglass reinforcement together has the potential to greatly expand the overall weight reduction to the end user as well as also the market penetration to both fiberglass and carbon fiber manufacturers. The results of this project demonstrate feasibility of a practical approach in structural design, cost-tradeoff analysis, and manufacturing hybrid structures with carbon fiber incorporated in specific locations for maximum benefit at minimum overall cost. With these results in hand, Owens Corning is now approaching industry partners with ORNL support to point out these benefits and map the next steps towards implementation of this identified approach. It is anticipated that the next phase will involve selection and demonstration of an actual manufacturing process such as robotic preforming in conjunction with liquid molding, thermoplastic or SMC compression molding, or other(s) to be employed for more specific application(s). 
Owens Corning has filed over 32 patents or applications in multiple countries protecting the $\mathrm{P} 4$ technology for enabling composite industry preforming capability. This includes random discrete bundles or oriented continuous fiber forms, along with hybrids of for example, carbon fiber and glass fiber. Several customers of Owens Corning currently use the P4 process and are evaluating the P4 process for hybrid fibers and preforms. The $\mathrm{P} 4$ process is known to demonstrate $95-98 \%$ yield with minimal waste depending on the preform complexity. This is the industry benchmark for glass fiber and carbon fiber preforming of large complex parts including the latest developments for BMW iseries.

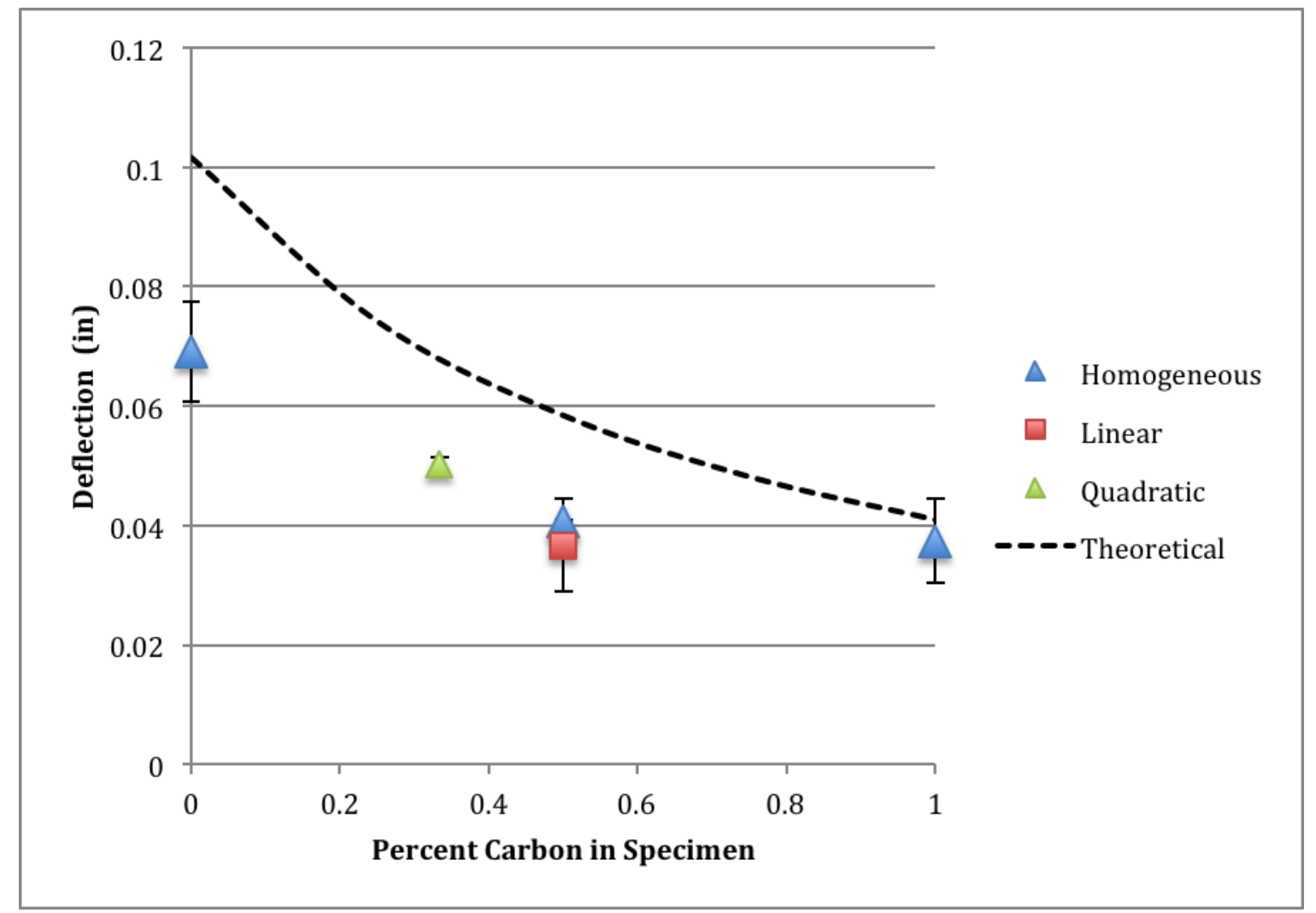

Figure 8. Results of hat section testing at Owens Corning.

\subsection{CONCLUSIONS}

Owens Corning is the world's largest glass fiber reinforcement supplier. In the industries served, the transportation sector is one of the largest users of glass fiber reinforcement. The transportation sector is focused on reducing weight through drive train efficiencies and through increasing utilization of lighter weight materials. In a lightweight hybrid composite there are different composite processes used by the supply or value chain depending on the function. Automotive body panels use SMC and P4 preforms for structural RTM. This work focuses on hybrid preforms that can be implement in these and other processes to enable synergy of carbon fiber for stiffness and glass for allowable strain (especially where subjected to instantaneous loading). The preform integrates the carbon and glass to their best function for synergy in the final part.

This project has demonstrated feasibility of a very practical approach to implementation of hybrid carbon-glass solutions that can realize most of the benefits of carbon fiber composites at much lower 
cost. The use of advanced materials such as carbon composites is generally conceded as offering a significant weight reduction, but this weight reduction is achieved at a relatively high cost. The project team evaluated and demonstrated material options that reduce weight compared to conventional materials, but also reduce cost when compared to carbon fiber composites. This was accomplished through the use of hybrid glass/carbon composites with selective placement of the different materials throughout the volume of the part. A computational framework was established that includes prediction of elastic and strength properties based on fiber architecture, as well as analysis of a structural bending element with selective fiber placement. Experimental work was performed to verify these predictions. A cost-weight optimization methodology was established, evaluated and shown to provide about $45-55 \%$ mass savings while increasing the cost by about $25-50 \%$ when compared to all glass and 13-14\% mass savings (and similar cost savings) versus uniformly distributed carbon fiber hybrids of the same fiber fraction. This optimized carbon-glass fiber composite manufacturing method delivers markedly higher value, with better potential for market penetration and thus greater impact on US energy security, than does a carbon fiber composite. 


\section{PARTNER BACKGROUND}

Owens Corning develops, manufactures and markets insulation, roofing, and fiberglass composites. Global in scope, the company's market-leading businesses use their deep expertise in materials, manufacturing and building science to develop products and systems that save energy and improve comfort in commercial and residential buildings. Through its glass reinforcements business, the company makes thousands of products lighter, stronger and more durable, especially in areas such as enhancing wind energy production and reducing energy usage in transportation. Ultimately Owens Corning people and products make the world a better place. Based in Toledo, Ohio, Owens Corning posted 2014 sales of $\$ 5.3$ billion and employs about 14,000 people in 25 countries. It has been listed as a Fortune $500 \AA$ company for more than 60 consecutive years. 